\section{Case Reports in Neurology}

Case Rep Neurol 2021;13:40-45

DOI: 10.1159/000510518
Published online: January 25, 2021

(C) 2021 The Author(s)

Published by S. Karger AG, Basel www.karger.com/crn

This article is licensed under the Creative Commons Attribution-NonCommercial 4.0 International License (CC BY-NC) (http://www.karger.com/Services/OpenAccessLicense). Usage and distribution for commercial purposes requires written permission.

\title{
SMART Syndrome Identification and Successful Treatment
}

\author{
Álvaro de Oliveira Franco ${ }^{\mathrm{a}}$ Eduardo Anzolin ${ }^{\mathrm{b}}$ \\ Marcio Schneider Medeiros ${ }^{c}$ Raphael Machado Castilhos ${ }^{c}$ \\ Rodrigo Targa Martins ${ }^{c}$ Humberto Luiz Moser Filho ${ }^{c}$ \\ aFaculty of Medicine, Universidade Federal do Rio Grande do Sul (UFRGS), Porto \\ Alegre, Brazil; bNeurosurgery Department, Hospital Cristo Redentor, Porto Alegre, Brazil; \\ 'Neurology Department, Hospital Nossa Senhora da Conceição (HNSC), Porto \\ Alegre, Brazil
}

\section{Keywords}

SMART syndrome $\cdot$ Aphasia $\cdot$ Radiation therapy $\cdot$ Pulse corticosteroid therapy $\cdot$ Calcium channel blocker

\begin{abstract}
Stroke-like migraine attacks after radiation therapy (SMART) syndrome is a rare late complication of brain irradiation. Patients commonly present recurrent attacks of headaches, seizures, and paroxysmal focal neurological deficits including aphasia, negligence, or hemianopsia. We report a 41-year-old male patient admitted to our emergency room with a reduced level of consciousness and global aphasia. One month prior to admission, he started with frequent headache attacks of moderate intensity and paroxysmal behavioral alterations, advancing to confusion, gait instability, language impairment, and somnolence. He had a history of medulloblastoma treated with surgical resection followed by craniospinal irradiation 21 years before symptom onset. After excluding more frequent causes for the patient's symptoms along with a suggestive image pattern, we started treatment for SMART syndrome with high-dose corticosteroid and calcium channel blocker verapamil. The patient gradually improved his level of consciousness and recovered from aphasia and gait instability without new seizures or neuropsychiatric symptoms. Follow-up brain magnetic resonance imaging showed resolution of the typical findings. This case displays a successful clinical evolution of a patient treated for SMART
\end{abstract}




\section{Case Reports in Neurology}

Case Rep Neurol 2021;13:40-45

\begin{tabular}{l|l}
\hline DOI: 10.1159/000510518 & $\odot 2021$ The Author(s). Published by S. Karger AG, Basel \\
\hline
\end{tabular} www.karger.com/crn

de Oliveira Franco et al.: SMART Syndrome Identification and Successful Treatment

syndrome in which identification of previous radiation treatment, exclusion of other etiologies, and prompt treatment institution were key for effectively tackling this disease.

\author{
(C) 2021 The Author(s) \\ Published by S. Karger AG, Basel
}

\title{
Introduction
}

Stroke-like migraine attacks following radiation therapy (SMART) is a rare syndrome that may appear as a late complication of brain radiotherapy [1]. There are about 100 cases of SMART syndrome reported in the literature since it was first described in 1995 [2]. The usual presentation consists of recurrent headache attacks associated with seizures and paroxysmal focal neurological deficits (e.g., aphasia, hemianopsia, and negligence), usually regarded as reversible or partially reversible [3-6]. A typical magnetic resonance imaging (MRI) pattern of SMART presents transient unilateral cortical gadolinium enhancement, increased T2 signal within temporal, parietal, and occipital cortices, with no restriction on diffusion-weighted imaging [4] and both hyper- and hypoperfusion reversible hemispheric abnormalities [7, 8].

We report the case of a patient with SMART syndrome with typical clinical and imaging features who was treated with corticosteroids and verapamil, showing fast resolution of symptoms. There is no clear consensus regarding effective treatment approaches to SMART; however, there are reports of patients with partial or complete recovery of symptoms after pulse therapy with corticosteroids [9]. There may also be a role for calcium channel blockers as an adjuvant drug [9].

\section{Case Report}

A 41-year-old man started with migraine-like attacks and behavioral changes that evolved in a few weeks to confusion and gait instability. After 30 days of the initial symptoms, he was brought to the emergency room when he presented a reduced level of consciousness and global aphasia. At admission, physical examination revealed an aphasic and stuporous patient in postictal state; there were no motor deficits or meningism. Vital signs were within the normal range. The patient had a history of desmoplastic medulloblastoma in his right cerebellar hemisphere at age of 20 . The lesion was treated with right occipital craniotomy resection followed by a 56 Gy two-dimensional cranial radiation therapy ( $36 \mathrm{~Gy} / 18$ fractions in the whole brain and $20 \mathrm{~Gy} / 10$ fractions in the posterior cranial fossa). The spinal cord was also irradiated with 30 Gy in 20 fractions. He had no other chronic diseases, no history of seizures, or ischemic cerebrovascular events.

At the neurology ward, the patient underwent a brain MRI that revealed new and prominent left hemisphere gyriform contrast enhancement associated with increased T2 and FLAIR signal involving predominantly the left occipital and temporal lobes (Fig. 1). MRI also showed small areas of restricted diffusion within the left occipital lobe, compatible with subacute infarction. Cerebrospinal fluid analysis showed only a slight increase in proteins $(71 \mathrm{mg} / \mathrm{dL})$. Electroencephalogram showed disorganized rhythms, without epileptiform discharges or periodic activity. Four-vessel angiography showed no vascular lesions.

The patient initially received carbamazepine $(800 \mathrm{mg} /$ day) for seizures, remaining free from new spells after recurrent seizures in the first few days of hospitalization. Intravenous

\section{Karger'=}




\section{Case Reports in Neurology}

Case Rep Neurol 2021;13:40-45

\begin{tabular}{l|l}
\hline DOI: 10.1159/000510518 & ○ 2021 The Author(s). Published by S. Karger AG, Basel \\
\hline
\end{tabular} www.karger.com/crn

de Oliveira Franco et al.: SMART Syndrome Identification and Successful Treatment

methylprednisolone (1,000 mg/day for 5 days, with tapering schedule with prednisone) and verapamil ( $160 \mathrm{mg} /$ day) were administered with fast recovery of consciousness and gait abnormalities. After corticosteroid therapy, aphasia had almost completely remitted, and he reported no headache crises. At follow-up, the patient remained with mild language impairment, his new MRI after 7 months showed resolution of previous abnormalities (Fig. 2), and the new electroencephalogram normalized.

\section{Discussion/Conclusion}

We report a patient that fulfilled the criteria for SMART syndrome [10] and was successfully treated with pulse corticosteroid therapy and calcium channel blocker. He partially recovered from his symptoms, rapidly remitting from his altered level of consciousness, headache attacks, and global aphasia.

SMART is a rare syndrome with just about 100 cases reported in the literature [2]. A high index of suspicion is necessary to make the diagnosis and a history of brain radiation (even in the remote past) is fundamental in this regard. Doses higher than $50 \mathrm{~Gy}$ of radiation are associated with SMART [6], but lower radiation regimens have also been reported to cause symptoms [11]. MRI studies are important to exclude other more common etiologies and identify gyriform contrast enhancement usually found in this syndrome. Our patient had typical manifestations, clinical course, and response to treatment. Most cases reported in the literature had complete recovery, but about $15 \%$ exhibited permanent sequelae in a large case series [2].

Corticosteroid is the most frequently used drug, although no controlled study has been conducted so far due to the rarity of the syndrome. Besides carbamazepine and corticosteroids, we administered the calcium channel blocker verapamil. Even though this drug was used previously only in a few case reports [9], it can have a beneficial effect considering the dysfunction in vasoreactivity involved in SMART pathophysiology [5]. Posterior reversible encephalopathy syndrome (PRES) is a more frequent entity that shares a similar clinical presentation with SMART syndrome. PRES also presents with headaches, neurological deficits, and seizures $[3,12]$ and preferably affects the parietal-temporal-occipital cortical regions. PRES has a mechanism that consists of combined vasoconstriction and vasodilation with vasculopathy patterns [13], which resembles the abnormal vascular reactivity and endothelial damage caused by irradiation that is hypothesized to underlie the SMART syndrome $[3,14]$. These similarities raise the possibility that both diseases may exhibit a comparable biological mechanism based on the dysfunctional cerebral vasoreactivity and may share a susceptibility to calcium channel blockers.

Interestingly, the patient presented multiple small ischemic lesions in his occipital lobe, which supports the associations between SMART syndrome and stroke, and reinforces the importance of implementing secondary stroke prevention [15]. Patients who presented ischemic stroke in their follow-up had their lesions located in the same sites of their SMARTrelated abnormalities, suggesting that the syndrome's underlying vascular dysfunction predisposes to cerebrovascular events and possible permanent symptoms [4]. Indeed, complete recovery occurs in $55-85 \%$ according to 2 case series $[2,4]$.

In patients with a history of brain irradiation, SMART renders an important differential diagnosis to consider before more aggressive procedures are performed, such as brain biopsy. The proper identification of this syndrome allows quick institution of corticosteroid-based

\section{Karger'=}




\section{Case Reports in Neurology}

Case Rep Neurol 2021;13:40-45

DOI: $10.1159 / 000510518$

(C) 2021 The Author(s). Published by S. Karger AG, Basel www.karger.com/crn

de Oliveira Franco et al.: SMART Syndrome Identification and Successful Treatment

therapy. The use of calcium channel antagonists may have a role in acute-phase treatment. Early management is important not only for remission of symptoms but also for prevention of important outcomes, such as stroke and epilepsy.

\section{Statement of Ethics}

The patient provided written informed consent to publish the case report, including images.

\section{Conflict of Interest Statement}

The authors have no conflicts of interest to declare.

\section{Funding Sources}

This research did not receive any specific grant from funding agencies in the public, commercial, or nonprofit sectors.

\section{Author Contributions}

Á.O.F., M.S.M., and H.L.M.F. designed and conceptualized the study; Á.O.F., E.A., and H.L.M.F. had major roles in the acquisition of the patient data and in the interpretation of the case and its results. All authors participated in drafting the manuscript for intellectual content. All authors read and approved the final manuscript.

\section{References}

1 Shuper A, Packer RJ, Vezina LG, Nicholson HS, Lafond D. 'Complicated migraine-like episodes' in children following cranial irradiation and chemotherapy. Neurology. 1995 Oct;45(10):1837-40.

2 Di Stefano AL, Berzero G, Ducray F, Eoli M, Pichiecchio A, Farina LM, et al. Stroke-like events after brain radiotherapy: a large series with long-term follow-up. Eur J Neurol. 2019 Apr;26(4):639-50.

3 Kerklaan JP, Lycklama á Nijeholt GJ, Wiggenraad RG, Berghuis B, Postma TJ, Taphoorn MJ. SMART syndrome: a late reversible complication after radiation therapy for brain tumours. J Neurol. 2011 Jun;258(6):1098104.

4 Black DF, Morris JM, Lindell EP, Krecke KN, Worrell GA, Bartleson JD, et al. Stroke-like migraine attacks after radiation therapy (SMART) syndrome is not always completely reversible: a case series. AJNR Am J Neuroradiol. 2013 Dec;34(12):2298-303.

5 Haller V, Dashti D, Peters N. SMART - Not Always Only “Stroke-Like”. Headache. 2018 Oct;58(9):1465-8.

6 Singh AK, Tantiwongkosi B, Moise AM, Altmeyer WB. Stroke-like migraine attacks after radiation therapy syndrome: case report and review of the literature. Neuroradiol J. 2017 Dec;30(6):568-73.

7 Wai K, Balabanski A, Chia N, Kleinig T. Reversible hemispheric hypoperfusion in two cases of SMART syndrome. J Clin Neurosci. 2017 Sep;43:146-8.

8 Nar Senol P, Gocmen R, Karli Oguz K, Topcuoglu MA, Arsava EM. Perfusion imaging insights into SMART syndrome: a case report. Acta Neurol Belg. 2015 Dec;115(4):807-10.

9 Jia W, Saito R, Kanamori M, Iwabuchi N, Iwasaki M, Tominaga T. SMART (stroke-like migraine attacks after radiation therapy) syndrome responded to steroid pulse therapy: report of a case and review of the literature. eNeurologicalSci. 2018 May;12:1-4.

\section{Karger'=}




\section{Case Reports in Neurology}

\begin{tabular}{l|l}
\hline Case Rep Neurol 2021;13:40-45 \\
\hline DOI: 10.1159/000510518 & $\begin{array}{l}\text { @ 2021 The Author(s). Published by S. Karger AG, Basel } \\
\text { www.karger.com/crn }\end{array}$ \\
\hline
\end{tabular}

de Oliveira Franco et al.: SMART Syndrome Identification and Successful Treatment

10 Ramanathan RS, Sreedher G, Malhotra K, Guduru Z, Agarwal D, Flaherty M, et al. Unusual case of recurrent SMART (stroke-like migraine attacks after radiation therapy) syndrome. Ann Indian Acad Neurol. 2016 JulSep;19(3):399-401.

11 Bartleson JD, Krecke KN, O'Neill BP, Brown PD. Reversible, strokelike migraine attacks in patients with previous radiation therapy. Neuro Oncol. 2003 Apr;5(2):121-7.

12 Kim JH, Brown SL, Jenrow KA, Ryu S. Mechanisms of radiation-induced brain toxicity and implications for future clinical trials. J Neurooncol. 2008 May;87(3):279-86.

13 Bartynski WS. Posterior reversible encephalopathy syndrome, part 2: controversies surrounding pathophysiology of vasogenic edema. AJNR Am J Neuroradiol. 2008 Jun;29(6):1043-9.

14 Yamada MK. A link between vascular damage and cognitive deficits after whole-brain radiation therapy for cancer: A clue to other types of dementia? Drug Discov Ther. 2016;10(2):79-81.

15 Takahashi H, Kimura T, Yuki N, Yoshioka A. Stroke-like Migraine Attacks after Radiation Therapy (SMART) Syndrome Followed by Cerebral Infarction. Intern Med. 2018 Jul;57(13):1921-4.
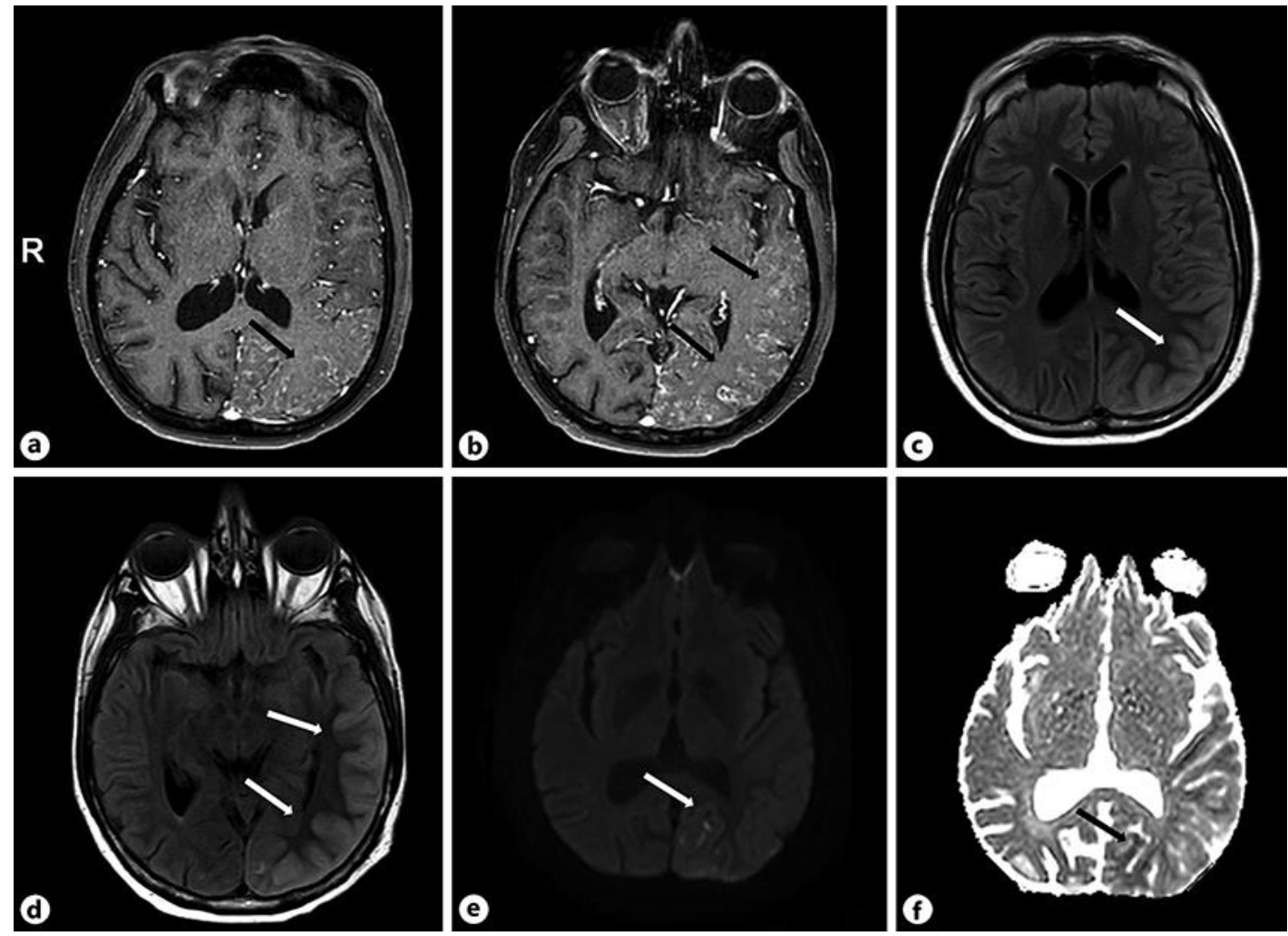

Fig. 1. Pretreatment brain magnetic resonance images. a, b Cortical gyriform enhancement involving the left occipital and temporoparietal lobes (black arrows) on axial T1 gadolinium-enhanced image. $\mathbf{c}$, d Axial FLAIR images showing cortical hyperintensities within the left occipital and temporoparietal lobes (white arrows), sparing subcortical white matter. e Axial DWI showing small areas of restricted diffusion in the left occipital lobe (white arrow), compatible with subacute infarction. $f$ Corresponding ADC image (black arrow). FLAIR, fluid-attenuated inversion recovery; DWI, diffusion-weighted imaging; ADC, apparent diffusion coefficient; $\mathrm{R}$, right side. 
Case Reports in Neurology
Case Rep Neurol 2021;13:40-45

DOI: $10.1159 / 000510518$

(c) 2021 The Author(s). Published by S. Karger AG, Basel www.karger.com/crn
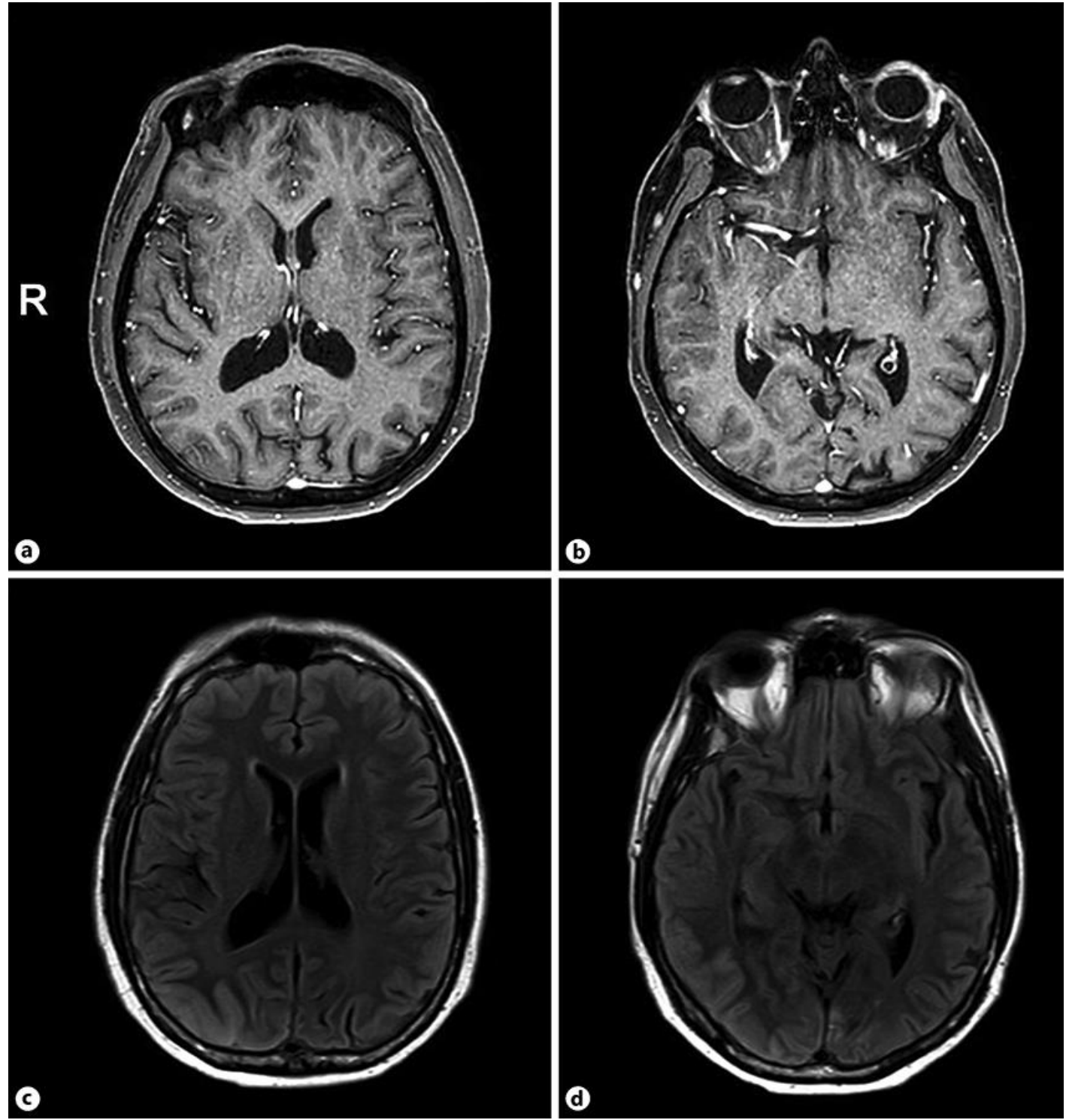

Fig. 2. Follow-up magnetic resonance images after 7 months. a, b Axial T1 gadolinium-enhanced images showing a marked reduction in contrast enhancement of the involved areas. c, $\mathbf{d}$ Axial FLAIR images showing resolution of cortical hyperintensities within the left occipital and temporoparietal lobes. FLAIR, fluidattenuated inversion recovery; R, right side. 